\title{
Real-Time PCR and Real-Time RT-PCR applications in food labelling and gene expression studies
}

\author{
Arash Kashani ${ }^{1}$, Aduli Enoch Othniel Malau-Aduli ${ }^{1,2, *}$ \\ ${ }^{1}$ Animal Science and Genetics, Tasmanian Institute of Agriculture, School of Land and Food, Faculty of Science, Engineering and \\ Technology, University of Tasmania, Private Bag 54 Sandy Bay, Hobart, Tasmania 7001, Australia \\ ${ }^{2}$ School of Veterinary and Biomedical Sciences, Faculty of Health, Medicine and Molecular Sciences, James Cook University, \\ Townsville, Queensland 4811, Australia
}

Email address:

Aduli.MalauAduli@utas.edu.au (A. E. O. Malau-Aduli), aduli.malauaduli@jcu.edu.au (A. E. O. Malau-Aduli)

\section{To cite this article:}

Arash Kashani, Aduli Enoch Othniel Malau-Aduli. Real-Time PCR and Real-Time RT-PCR Applications in Food Labelling and Gene Expression Studies. International Journal of Genetics and Genomics. Vol. 2, No. 1, 2014, pp. 6-12. doi: 10.11648/j.ijgg.20140201.12

\begin{abstract}
Polymerase chain reaction (PCR) as a scientific invention, has revolutionized molecular biology and led to real-time PCR and later, real-time reverse transcription PCR (Real-Time RT-PCR). These two techniques enable scientists to conduct PCR detection of amplified gene products and expression analysis of targeted genes. Quantitative polymerase chain reaction (qPCR), also called real-time polymerase chain reaction, is a recent modification to PCR that utilizes fluorescent reporter molecular techniques to monitor the production of amplified products during each cycle of the PCR reaction, and enables both detection and quantification of specific sequences in complex mixtures. Over the past decade, real-time PCR applications have rapidly changed the nature of molecular science and become widely used tools in molecular genetics research. Real-time PCR permits specific, sensitive and reproducible manipulation of nucleic acids by combining the nucleic acid amplification and detection steps using gel electrophoresis. Hence, it almost eliminates the need for DNA sequencing or Southern blotting for amplicon identification. One of the many versions of PCR is real-time RTPCR which has become one of the most broadly used gene amplification and expression methods in molecular biology research. Real-time RT-PCR is commonly employed to discover RNA expression levels through the creation of complimentary DNA (cDNA) transcripts from RNA, and it is frequently confused with real-time PCR. Food labelling provides very important information to help both producers and consumers to make informed choices about healthier and safer food. The process that information from a gene is used in the synthesis of a functional gene product is called gene expression. It enables scientists decipher the functions of genes. Food labelling and gene expression are fundamental to studying the relationships between the human genome, nutrition and health in a relatively new specialist field called nutritional genomics. Nutritional genomics is expected to revolutionize the way health professionals and dieticians treat people in the future. Thus, it is anticipated that the focus of nutritional genomics research will in the future, shift to determining the right type of food for an individual based on his or her genomic compatibility and therefore aid in avoiding foods that are an inappropriate match and could potentially impact negatively on the individual's health. This paper reviews the importance and power of real-time PCR application in food labelling and nutritional genomics, types of fluorescentbased chemistry procedures developed for real-time PCR detection, real-time RT-PCR application in gene expression studies and the great potential of combining these technologies for animal molecular genetics research in sheep and fish.
\end{abstract}

Keywords: PCR, Real-Time PCR, Real-Time RT-PCR, Gene Expression

\section{Introduction}

Kary Mullis in 1984 made a revolution in science by inventing the polymerase chain reaction (PCR)[1]. PCR utilizes a pair of primers, each hybridizing to one strand of a double-stranded DNA target, with the pair spanning a region that is exponentially reproduced. The hybridized primer creates a complimentary strand through a sequential addition of deoxynucleotides [2, 3]. This process is summarized in the following steps (i) at $>90^{\circ} \mathrm{C}$, the double-stranded DNA is separated (ii) at $50-75^{\circ} \mathrm{C}$ primer annealing occurs, and (iii) at $72-78^{\circ} \mathrm{C}$ optimal extension is 
achieved as depicted in Fig. 1 [2-4].

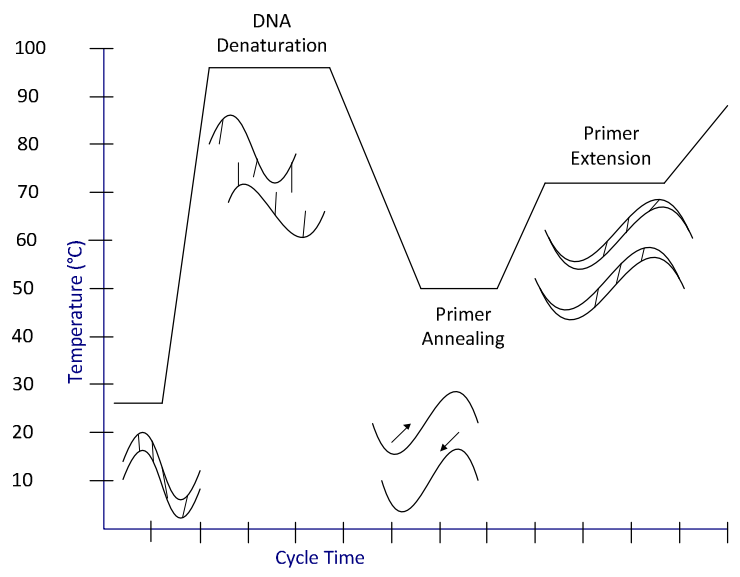

Figure 1. The PCR cycle.

Some of the gold standards such as cell culture and serological assays have been displaced by the introduction of conventional PCR which is used to obtain quantitative data with promising results [1-3]. However, electrophoresis of the nucleic acids using ethidium bromide and visual or densitometric analysis of the resulting bands after irradiation by ultraviolet light are required for traditional detection of amplified DNA [3, 5, 6].

In contrast to conventional assays, the theory of the detection of amplicons by visualization as the amplification progresses, is highly regarded $[2,3]$. This modification to PCR is called real-time or quantitative polymerase chain reaction (qPCR) [2, 7], and was first introduced by Higuchi and colleagues in 1992 [2]. Real-time PCR permits accurate detection and quantification of specific nucleic acids in a complex mixture $[2,8]$. In real-time PCR, the procedure follows the general principles of PCR and it is achieved by monitoring the amplification of a target sequence using fluorescence [1,2].

Over the past decade, real-time PCR has become a common and broadly used tool for detecting and quantifying expression profiles of selected genes by coupling it with reverse transcription $[1,2,9]$. By the combination of these two technologies (reverse transcription polymerase chain reaction and real-time RTPCR), the quantitative measurement of RNA transcription levels is accomplished $[1,2,8]$

This paper's objective is to review published literature on the applications of real-time PCR and real-time RT-PCR in food labeling and gene expression studies in sheep and fish.

\section{Real-Time PCR Applications}

\subsection{The Food Industry}

In the modern diet, food labeling regulations require accurate declaration of product ingredients. This has become necessary because food adulteration is a common problem in processed foods industry. Adulteration occurs in the beef industry through the addition of minced meats [10,
11], just as much as the addition of mixed milk to dairy products occurs in the dairy industry [12]. In order to ensure food safety for consumers who may have specific food allergies and to gain consumers' trust as well as minimize possible economic losses, several analytical methods have been developed to verify food labeling statements [10-12].

In the past few years, protein-based methods and DNA analysis have been used to correctly label food products. However, protein-based methods have had limited success in cooked meat products due to protein denaturation during processing heat and pressure [11, 12]. On the other hand, due to the high stability and unique variability of DNA molecules, they have been used as target compounds for species identification [10, 11]. Among DNA-based methods, PCR techniques are highly accurate and relatively fast, hence their successful applications in the meat and dairy industries [10-12]. However, conventional PCR methods appear to lack quantitative capabilities.

In the recent past, the need for methods giving quantitative results has grown following the introduction of labeling obligations made by Authorized Food Control Agencies [10, 11]. Among PCR-based methods which monitor the exponential amplification of target-specific DNA, Real-Time PCR has demonstrated the highest improvement in increased fluorescence signal $[10,11,13]$.

A number of studies have successfully developed realtime PCR methods for the food and dairy industries. For example, TagMan-based real-time PCR methods for the detection and separation of chicken from turkey meat [13] and distinguishing between pork, chicken, beef, mutton and horse meat [11], have been published. Furthermore, multiplex real-time PCRs for the quantification of DNA from beef, pork, horse and sheep [10], and real-time quantitative PCR assays for the detection of goat milk in sheep milk, have also been developed [12] (Table 1).

Table 1. The application of real-time PCR in food labeling industry.

\begin{tabular}{|c|c|c|}
\hline Study & Sample & Reference \\
\hline Detection of chicken and turkey meat & $\begin{array}{l}\text { Raw and } \\
\text { cooked meat }\end{array}$ & [13] \\
\hline $\begin{array}{l}\text { Detection method for distinguishing pork, } \\
\text { chicken, beef, mutton, and horse flesh }\end{array}$ & Food & [11] \\
\hline $\begin{array}{l}\text { Multiplex real-time PCR for the detection } \\
\text { and quantification of DNA from beef, } \\
\text { pork, horse and sheep }\end{array}$ & $\begin{array}{l}\text { Raw and } \\
\text { cooked meat }\end{array}$ & [10] \\
\hline $\begin{array}{l}\text { Quantitative detection of goat milk in } \\
\text { sheep milk by real-time PCR }\end{array}$ & Milk & [12] \\
\hline
\end{tabular}

The tremendous utility and diversity of possible areas of application of real-time PCR techniques make it affordable for most laboratories and industries to use in research and 
food inspection programs.

\subsection{Nutritional Genomics}

In line with increasing world population, meat and milk consumption is predicted to increase globally. The risk of cardiovascular disease, some cancers and diabetes has been shown to be related to dietary intake of unsaturated fatty acids (UFA) [14, 15]. In addition, animal products have been criticized for their high content of saturated fatty acids (SFA). Therefore, the nutritional modification of animal diets to increase the proportion of UFA at the expense of SFA has been the subject of continuous research interest in meat, milk and eggs $[14,15]$.

Nutrients can interact and modulate molecular mechanisms of physiological functions in an organism. Erroneous scientific conclusions and misinformed nutritional recommendations have resulted from performing population-scale epidemiological studies in the absence of genetic knowledge [14]. To overcome such issues and understand more about the relationship between genes and diets, the field of nutrition has begun to introduce technologies and supporting analytical software to elucidate the interactions between diets and genes [14, 15].

Nutritional genomics is divided into two disciplines: Nutrigenomics and Nutrigenetics. Nutrigenomics examines the effect of nutrients and dietary ingredients on health by altering the genome, proteome and metabolome. In this regard, there are scientific attempts to link the resulting phenotypic variation to differences in the genetic response of the whole biological system. On the other hand, nutrigenetics analyses the effect of genetic variations on the interaction between diet and health. It aims to investigate how the genetic constitution of an individual coordinates their response to diet, hence studies the underlying genetic polymorphisms $[14,16]$.

As an example, a nutrigenetics study related to cardiovascular disease and cancer was conducted in Singapore [16]. Singapore's population includes large segments of diverse ethnic backgrounds; comprising Malays, Chinese and Indians, and it has undergone a very rapid socio-economic development [16]. Due to this rapid development, life expectancy has risen, and mortality figures have changed from malnutrition and infectious diseases, to cardiovascular disease and cancer, which represent the top two causes of death in Singapore [16]. Living in this ethnic heterogeneity as an integrated community within a homogenous environment, provided an interesting opportunity to study the impact of ethnicity on cardiovascular and cancer disease throughout the rapid economic transition [16].

The results revealed that in relation to metabolic and cardiovascular diseases, the epidemiological transition had not affected all ethnic groups equally. The study indicated that Singaporeans of Indian origin appeared to be at the highest risk of susceptibility to cardiovascular disease, followed by the intermediate rate in Malays and the lowest risk in Chinese [16].

\section{Fluorescence-Based Chemistry Versus SYBR-Green}

One of the main problems of research within a clinical diagnostic setting, is the detection and quantification of gene re-arrangement, amplification, translocation or deletion $[2,6]$. However, real-time PCR has become a well-established procedure for quantifying the levels of gene expression.

There are several fluorescent-based chemistry procedures developed for real-time PCR detection, which are classified into four main types [4]

- Hydrolysis probe (e.g. TagMan)

- Hairpin probes (e.g. Molecular beacons)

- $\quad$ Fluorescent labeled hybridization probes (e.g. FRET)

- DNA intercalating dyes

Hydrolysis Probes

Hydrolysis probes are designed to increase the specificity of real-time PCR assays and are represented by TagMan chemistry principles. The principle relies on the 5'3' exonuclease activity of fluorescence upon probe hydrolysis to detect PCR product accumulation [2, 17]. TagMan probe is labeled with fluorophore and covalently attached to the 5' end, and a quencher dye on the 3' end [17] Similar to other PCR methods, the resulting fluorescence signal allows the quantitative measurement of product accumulation during the exponential stages of PCR. However, the specificity of detection is significantly increased by the TagMan probe [2, 17].

Hairpin Probes

The presence of specific nucleic acids in homogenous solutions is often reported by oligonucleotide hybridization probes also known as molecular beacons [2, 17]. Molecular beacons are the simplest among hairpin probes and consist of a loop-shaped region of sequence-specific primers flanked by two inverted repeats [2, 17]. Molecular beacons represent a non-radioactive method for detecting specific sequences of nucleic acids [2,17].

Fluorescent Labeled Hybridization Probes

Hybridization probes are fragments of DNA or RNA used to detect the presence of nucleotide sequences that are complementary to the sequence in the probe [17]. Hybridization probes can be used in either a three- or fouroligonucleotide assay. In the four-oligonucleotide method, PCR primers and two sequence-specific probes bind next to each other in a head-to-tail arrangement [2, 17]. To ensure hybridization of the probe to its target sequence, the probe is tagged as a radioactive or fluorescent molecular marker $[2,17]$. Hybridization probes are used in the field of microbial ecology in order to determine the presence of microbial species, genera, or microorganisms [2, 17].

DNA Intercalating Dyes

DNA intercalating dyes start emitting fluorescence when bound to double-stranded DNA (dsDNA). During PCR cycling, the double-stranded PCR product accumulates more dye, binds and emits fluorescence $[2,17]$. Hence, the fluorescence intensity increases proportionally to dsDNA concentration. In this technique, one dye can be used for 
different gene assays, which makes it very flexible $[2,17]$.

In probe-based chemistry, real-time PCR assays allow the use of very small amplicons and internal probes which bind to the desired specific sequence within the amplicon. As a result, specific and efficient amplification is accomplished [4]. However, the possible limitations of these assays include the design and availability of appropriate primers and probes that must adapt to fixed PCR conditions. The most direct, simple and inexpensive fluorescent system developed for real-time PCR is SYBR Green I, and it is based on the binding of the fluorescent dye unto the PCR product $[4,6]$.

\section{SYBR Green I}

SYBR Green I is an asymmetrical cyanine dye. It involves the incorporation of the SYBR Green I dye, whose fluorescence under ultraviolet rays, greatly increases when it is bound to the minor groove of the double helical DNA. It is used as a nucleic acid stain in molecular biology [4]. The advantage of using SYBR Green I dye is that it allows the interpretation of DNA melting curves in order to distinguish the specific amplicon of the PCR product from false positive signals resulting from non-specific amplification or primer dimers [2, 4, 18].

\subsection{Real-Time RT-PCR Method for Quantifying Gene Expression}

During the last century, advancements in bioscience have assisted in our comprehensive understanding of the molecular mechanisms of phenotypic expression of genotypes [1,9]. However, knowledge of the functions of a major part of the genome is still limited or unknown, and the relationship between enzymes, small molecules and signaling substances is quite limited $[1,8]$. Gene expression analysis can yield valuable clues about gene function, thus it has been widely used to identify the type of cells or tissues where a gene is expressed [2], detecting the relationship between ecologically influenced or a defined biological state (e.g., development, differentiation , disease), cellular expression patterns [1], and discovering a change in gene expression level in response to a specific biological stimulus (e.g., pharmacological agent or growth factor) [2].

Conventional RT-PCR was widely used for gene-specific mRNA quantification during the early days of the introduction of real-time RT-PCR[8]. This method is called quantitative endpoint RT-PCR analysis. It is not able to determine the initial quantity of template molecules for a gene-specific PCR, due to reliance on measuring the end point of a PCR reaction by ethidium bromide visualization of the DNA product separated by gel electrophoresis [2, 8 , 9]. The amount of amplicon at the end of amplification cycles depends on the input amount, variable kinetics of the PCR reaction and technical variations occurring during the reaction time frame $[9,18]$. This variability is shown in "Fig.2" compared to real-time RT-PCR which improves upon endpoint RT-PCR by measuring target amplification early in the reaction while amplification is continuing most efficiently $[1,2,18]$.

\subsection{Comparison of Gene Expression Analysis between Real-Time RT-PCR and Northern Blot Analysis and RNase Protection Assays}

There are major advantages of using real-time PCR compared to conventional semi-quantitative PCR. Gene expression analysis using northern blot technique and RNase protection assays is time consuming, and also difficult to reliably generate accurate measurements of gene expression levels [1, 2, 18]. The application of real-time RT-PCR extends several advantages over the other methods, including requiring small amounts of sample to start, its power to reproduce rapid and accurate data, and its capacity for analyzing multiplex genes at a time [2, 7].

To work with extremely low amounts of mRNA, realtime RT-PCR is the technique of choice. By using an internal control, Real-time RT-PCR ensures normalization of differences in the kinetics of the reverse transcription process, and adequately replaces other conventional methods [2, 8]. In addition, multiplex real-time RT-PCR is desirable to examine multiple gene identification based on the utilization of fluorochomes and analysis of melting curves of the amplified products [1].

Real-time RT-PCR technology is now available for many livestock species, and animal researchers are beginning to use the technology to address issues of importance to animal agriculture (Table 2).

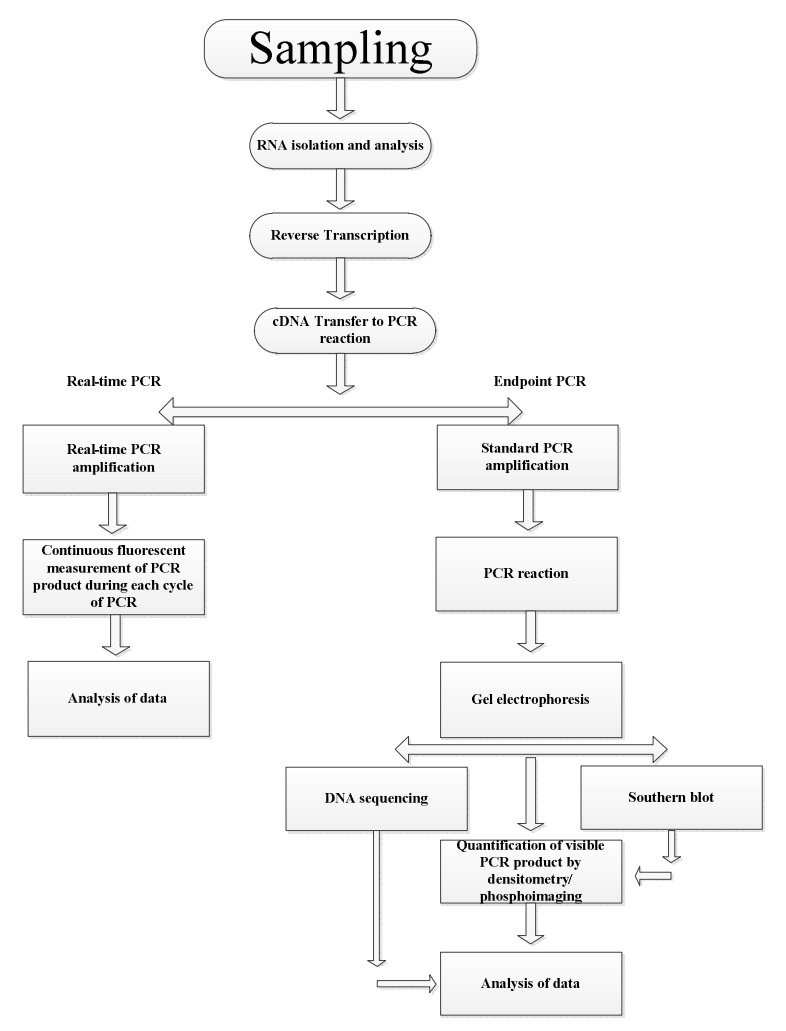

Figure 2. Comparison of end-point RT-PCR and real-time RT-PCR. 


\section{Discussion}

Since the invention of PCR in 1984, there has been modification to the process of amplifying DNA and an evolution in the field of gene expression studies. To our knowledge, documentation and systematic review of how the PCR process has evolved remains scanty, hence the need for this review to provide the scientific community with the current applications of PCR and RT-PCR techniques. In the past, real-time RT-PCR technique was largely used for gene expression analysis in microorganisms, but it is now being increasingly applied in nutritional genomics to study ruminants, porcines and fish $[2,13]$. For example, in a study of Euryhaline fish (Lates calcarifer), gene expression analysis revealed that dietary oils lacking long-chain polyunsaturated fatty acids (LCPUFA) up-regulated key LC-PUFA biosynthesis genes in the muscle and liver tissues [19]. In a similar study, realtime RT-PCR was employed to examine the gene expression of n-3 LC-PUFA biosynthesis in the white muscle and liver of Atlantic salmon [20]. In this study, real-time RT-PCR analysis demonstrated that Echium oilfed fish had higher n-3 LC-PUFA levels in both liver and white muscle tissues compared to rapeseed oil-fed fish (Table 2) [20].

Gene expression analysis using real-time RT-PCR has been employed for studying the differences in inter-species relationships in veterinary medicine, hence the need for conducting research in specific animal species to obtain accurate information of the constitutive expression of multi-drug transporters [21]. Another example is the gene expression and transport efflux activity of P-glycoprotein in sheep liver and small intestines (Table 2) [21].

Real-time RT-PCR is a powerful tool for analyzing mRNA expression of a gene(s) in different species in order to investigate the existence of homology or further phylogenetic relationships (e.g., Rab-related protein Rab2A (Rab2A), Rab-related protein Rab-3A (Rab3A) and Rab-related protein Rab-7A (Rab7A) genes in black-boned sheep [22], Lymphocyte-specific protein tyrosine kinase (LCK) and Cyclin-dependent kinase 2 (CDK2) genes from the black-boned sheep [23], and Sideroflexin 1 (Sfxn1), Snai homolog 2 (Snai2) and Protein cappuccino homolog (Cno) genes from black-boned sheep (Table 2) [24].

\section{Conclusion}

Real-time RT-PCR is a unique and powerful tool for the detection of mRNA and gene expression levels in various research fields. Despite its advantages, the extreme sensitivity of this technique can be a drawback. A slight DNA combination can lead to undesirable results. Also, planning and designing of quantification studies can be technically challenging. Furthermore, the application of Real-time RT-PCR in nutritional studies including omega-3 and omega-6 fatty acid syntheses, is still limited. Nevertheless, it is predicted that real-time RT-PCR as a technique for investigating gene expression in nutritional genomics research, will continue to grow.

In our Animal Science and Genetics Research Laboratory at the University of Tasmania, Australia, we employ real-time RT-PCR technique to identify expression profiles of genes affecting fat and protein biosynthesis and metabolism in the liver, heart, muscle, kidney and adipose tissues in genetically divergent purebred and crossbred Australian sheep supplemented with unconventional dietary protein sources like the microalga called Spirulina. We are aiming to trace the expression profiles of fat-related genes in different sheep tissues. This would allow us to determine a balanced level of dietary protein from gene expression data to increase the omega- 3 and omega- 6 contents of red meat among Australian crossbred sheep. It is hoped that the current paper's objective to review published literature on the applications of real-time PCR and real-time RT-PCR will give the scientific community a systematic and updated information on the evolution and application of PCR in gene expression and food labelling studies.

Table 2. Applications of Real-time RT-PCR Technology in Animal Research.

\begin{tabular}{|c|c|c|c|c|}
\hline Purpose & Species & Tissue & Gene & Reference \\
\hline $\begin{array}{l}\text { P-glycoprotein in sheep liver and small intestine gene expression and } \\
\text { transport efflux activity }\end{array}$ & Sheep & Liver & $\mathrm{ABCB} 1$ & {$[21]$} \\
\hline $\begin{array}{l}\text { Analysis on cDNA sequence, mRNA expression and imprinting } \\
\text { status of Dlk1 gene in goats }\end{array}$ & Sheep & Various parts & Dlk1 & [25] \\
\hline $\begin{array}{l}\text { The quantification of prion gene expression in sheep using real-time } \\
\text { RT-PCR }\end{array}$ & Sheep & $\begin{array}{l}\text { neocortex, cerebellum, } \\
\text { thalamus, obex, } \\
\text { hippocampi, conarium and } \\
\text { spinal cord }\end{array}$ & PrP & [26] \\
\hline $\begin{array}{l}\text { Molecular cloning, sequence characterization and tissue transcription } \\
\text { profile analyses of two genes: LCK and CDK2; from Black-boned } \\
\text { sheep }\end{array}$ & Sheep & $\begin{array}{l}\text { Spleen, skin, kidney, lung, } \\
\text { liver \& heart }\end{array}$ & LCK \& CDK2 & [23] \\
\hline $\begin{array}{l}\text { Molecular cloning, sequence identification and tissue expression } \\
\text { profile of three novel gene S } f x n 1 \text {, Snai } 2 \text { and Cno from Black-boned } \\
\text { sheep }\end{array}$ & Sheep & $\begin{array}{l}\text { Leg muscle, kidney, skin, } \\
\text { Longissimus dorsi muscle, } \\
\text { spleen, heart \& liver }\end{array}$ & $\begin{array}{l}\text { Sfxn1, Snai2 \& } \\
\text { Cno }\end{array}$ & [24] \\
\hline
\end{tabular}




\begin{tabular}{|c|c|c|c|c|}
\hline Purpose & Species & Tissue & Gene & Reference \\
\hline $\begin{array}{l}\text { Isolation, sequence identification and expression profile of three } \\
\text { novel genes } R a b 2 A, R a b 3 A \text { and } R a b 7 A \text { from black-boned sheep }\end{array}$ & Sheep & $\begin{array}{l}\text { Leg muscle, kidney, skin, } \\
\text { Longissimus dorsi muscle, } \\
\text { spleen, heart \& liver }\end{array}$ & $\begin{array}{l}\text { Rab2A, Rab3A \& } \\
\operatorname{Rab7A}\end{array}$ & [22] \\
\hline $\begin{array}{l}\text { An extended feeding history with a stearidonic acid enriched diet } \\
\text { from parr to smolt increase n- } 3 \text { long-chain polyunsaturated fatty } \\
\text { acids biosynthesis in white muscle and liver of Atlantic salmon } \\
\text { (Salmo salar L.) }\end{array}$ & $\begin{array}{l}\text { Atlantic } \\
\text { salmon }\end{array}$ & Muscle \& liver & $\begin{array}{l}\Delta 6 \text { desaturase, } \Delta 5 \\
\text { desaturase, } \\
\text { elongase }\end{array}$ & [20] \\
\hline $\begin{array}{l}\text { Up-regulated desaturase and elongase gene expression promoted } \\
\text { accumulation of polyunsaturated fatty acid (PUFA) but not long- } \\
\text { chain PUFA in Lates calcarifer, a tropical euryhaline fish fed a } \\
\text { stearidonic acid-and } \gamma \text {-linoleic acid-enriched diet }\end{array}$ & Fish & Liver \& skeletal muscle & $\begin{array}{l}\text { Ubq, EF1- } \alpha, \beta- \\
\text { actin, FAE \& } \\
\text { FAD6 }\end{array}$ & [19] \\
\hline
\end{tabular}

\section{References}

[1] Deepak, S. A., Kottapalli, K. R., Rakwal, R., Oros, G., Rangappa, K. S., Iwahashi, H., Masuo, Y. \& Agrawal, G. K. 2007., Real-Time PCR: Revolutionizing Detection and Expression Analysis of Genes. Current Genomics, 2007. 8(4): p. 234-251.

[2] Fraga, D., T. Meulia, and S. Fenster, Real-Time PCR, in Current Protocols Essential Laboratory Techniques. 2008, John Wiley \& Sons, Inc.

[3] Mackay, I.M., K.E. Arden, and A. Nitsche, Real-time PCR in virology. Nucleic Acids Research, 2002. 30(6): p. 12921305.

[4] Fajardo, V., González, I., Rojas, M., García, T. \& Martín, R. 2010, A review of current PCR-based methodologies for the authentication of meats from game animal species. Trends in Food Science \& Technology, 2010. 21(8): p. 408-421.

[5] Hoffmann, B., Beer, M., Reid, S. M., Mertens, P., Oura, C. A. L., Vanrijn, P. A., Slomka, M. J., Banks, J., Brown, I. H., Alexander, D. J. \& King, D. P. 2009., et al., A review of RTPCR technologies used in veterinary virology and disease control: Sensitive and specific diagnosis of five livestock diseases notifiable to the World Organisation for Animal Health. Veterinary Microbiology, 2009. 139(1-2): p. 1-23.

[6] Ponchel, F., Toomes, C., Bransfield, K., Leong, F., Douglas, S., Field, S., Bell, S., Combaret, V., Puisieux, A., Mighell, A., Robinson, P., Inglehearn, C., Isaacs, J. \& Markham, A. 2003., Real-time PCR based on SYBR-Green I fluorescence: An alternative to the TaqMan assay for a relative quantification of gene rearrangements, gene amplifications and micro gene deletions. BMC Biotechnology, 2003. 3(1): p. 18.

[7] Schefe, J., Lehmann, K., Buschmann, I., Unger, T. \& Funkekaiser, H. 2006., Quantitative real-time RT-PCR data analysis: current concepts and the novel "gene expression's C T difference" formula. Journal of Molecular Medicine, 2006. 84(11): p. 901-910.

[8] Shiao, Y.-H., A new reverse transcription-polymerase chain reaction method for accurate quantification. BMC Biotechnology, 2003. 3(1): p. 22.

[9] Bustin, S. A., Benes, V., Nolan, T. \& Pfaffl, M. W. 2005. , Quantitative real-time RT-PCR - a perspective. Journal of Molecular Endocrinology, 2005. 34(3): p. 597-601.

[10] Köppel, R., J. Ruf, and J. Rentsch, Multiplex real-time PCR for the detection and quantification of DNA from beef, pork, horse and sheep. European Food Research and Technology, 2011. 232(1): p. 151-155.

[11] Tanabe, S., Hase, M., Yano, T., Sato, M., Fujimura, T. \& Akiyama, H. 2007., A Real-Time Quantitative PCR Detection Method for Pork, Chicken, Beef, Mutton, and Horseflesh in Foods. Bioscience, Biotechnology, and Biochemistry, 2007. 71(12): p. 3131-3135.

[12] López-Calleja, I., González, I., Fajardo, V., Martín, I., Hernández, P. E., García, T. \& Martín, R. 2007., Quantitative detection of goats' milk in sheep's milk by realtime PCR. Food Control, 2007. 18(11): p. 1466-1473.

[13] Kesmen, Z., Yetiman, A. E., Şahin, F. \& Yetim, H. 2012., Detection of Chicken and Turkey Meat in Meat Mixtures by Using Real-Time PCR Assays. Journal of Food Science, 2012. 77(2): p. C167-C173.

[14] Mutch, D.M., W. Wahli, and G. Williamson, Nutrigenomics and nutrigenetics: the emerging faces of nutrition. The FASEB Journal, 2005. 19(12): p. 1602-1616.

[15] Woods, V.B. and A.M. Fearon, Dietary sources of unsaturated fatty acids for animals and their transfer into meat, milk and eggs: A review. Livestock Science, 2009. 126(1-3): p. 1-20.

[16] Fenech, M., El-Sohemy, A., Cahill, L., Ferguson, L. R., French, T. A. C., Tai, E. S., Milner, J., Koh, W. P., XIE, L., Zucker, M., Buckley, M., Cosgrove, L., Lockett, T., Fung, K. Y. C. \& Head, R. 2011., Nutrigenetics and Nutrigenomics: Viewpoints on the Current Status and Applications in Nutrition Research and Practice. Journal of Nutrigenetics and Nutrigenomics, 2011. 4(2): p. 69-89.

[17] Wong, M.L. and J.F. Medrano, Real-time PCR for mRNA quantitation. Biotechniques, 2005. 39(1): p. 75-85.

[18] Etienne, W., Meyer, M. H., Peppers, J. \& Meyer, R. A. 2004., Comparison of mRNA gene expression by RT-PCR and DNA microarray. Biotechniques, 2004. 36(4): p. 618-20, 622, 624-6.

[19] Alhazzaa, R., Bridle, A. R., Nichols, P. D. \& Carter, C. G. 2011., et al., Up-regulated Desaturase and Elongase Gene Expression Promoted Accumulation of Polyunsaturated Fatty Acid (PUFA) but Not Long-Chain PUFA in Lates calcarifer, a Tropical Euryhaline Fish, Fed a Stearidonic Acid- and $\gamma$-Linoleic Acid-Enriched Diet. Journal of Agricultural and Food Chemistry, 2011. 59(15): p. 84238434. 
[20] Codabaccus, B. M., Bridle, A. R., Nichols, P. D. \& Carter, C. G. 2011., et al., An extended feeding history with a stearidonic acid enriched diet from parr to smolt increases n3 long-chain polyunsaturated fatty acids biosynthesis in white muscle and liver of Atlantic salmon (Salmo salar L.). Aquaculture, 2011. 322-323(0): p. 65-73.

[21] Ballent, M., Wilkens, M. R., Maté, L., Muscher, A. S., Virkel, G., Sallovitz, J., Schröder, B., Lanusse, C. \& Lifschitz, A. 2013., P-glycoprotein in sheep liver and small intestine: gene expression and transport efflux activity. Journal of Veterinary Pharmacology and Therapeutics, 2013: p. n/a-n/a.

[22] He, Y., Liu, D., Xi, D., Yang, L., Tan, Y., Liu, Q., Mao, H. \& Deng, W. 2010., Isolation, sequence identification and expression profile of three novel genes Rab2A, Rab3A and Rab7A from black-boned sheep (Ovis aries). Molecular Biology, 2010. 44(1): p. 14-22.

[23] Yu, H., Chen, S., Xi, D., He, Y., Liu, Q., Mao, H. \& Deng, W. 2010., et al., Molecular cloning, sequence characterization and tissue transcription profile analyses of two novel genes: LCK and CDK2 ; from the Black-boned sheep (Ovis ariest). Molecular Biology Reports, 2010. 37(1): p. 39-45.

[24] Xi, D., He, Y., Sun, Y., Gou, X., Yang, S., Mao, H. \& Deng, W. 2011., et al., Molecular cloning, sequence identification and tissue expression profile of three novel genes Sfxn1, Snai2 and Cno from Black-boned sheep (Ovis aries). Molecular Biology Reports, 2011. 38(3): p. 1883-1887.

[25] Cao, G. L., Zhang, Y. J., Wang, J. M. \& Jiang, Y. L. 2010., et al., Analysis on cDNA sequence, mRNA expression and imprinting status of Dlk1 gene in goats. Molecular Biology Reports, 2010. 37(5): p. 2259-2264.

[26] Han, C.-X., H.-X. Liu, and D.-M. Zhao, The quantification of prion gene expression in sheep using real-time RT-PCR. Virus Genes, 2006. 33(3): p. 359-364. 